\title{
Pretreatment levels of serum osteoprotegerin and p53 protein and urine telomerase as prognostic factors affecting survival in Egyptian bladder cancer patients
}

\author{
RANIA BAKRY ${ }^{1}$, MOHAMED I. EL-SAYED ${ }^{2}$, HESHAM M. HAMZA ${ }^{3}$ and KHALED H. HASSAN ${ }^{4}$ \\ Departments of ${ }^{1}$ Clinical Pathology, ${ }^{2}$ Radiotherapy and ${ }^{3}$ Surgical Oncology, South Egypt Cancer Institute, Assiut University, \\ Assiut 71111; ${ }^{4}$ Department of Biochemistry, Faculty of Pharmacy (Boys), Al-Azhar University, Cairo 11566, Egypt
}

Received October 28, 2014; Accepted August 27, 2015

DOI: $10.3892 / 01.2015 .3925$

\begin{abstract}
A non-invasive marker is required for the diagnosis and follow-up of patients with bladder cancer. The aim of the current study was to evaluate the potential prognostic significance of serum osteoprotegerin (OPG), p53 protein and urine telomerase in patients with bladder cancer. For all patients, serum levels of OPG and p53 protein were determined using enzyme-linked immunosorbent assay (ELISA), and urine telomerase was assessed using a polymerase chain reaction ELISA technique. Patients were assigned into group 1 (cystectomy and adjuvant radiotherapy) or group 2 (transurethral resection and chemoradiotherapy). The results revealed that serum OPG and p53, and urine telomerase levels were significantly higher in bladder cancer patients compared with in healthy individuals $(\mathrm{P}<0.0001)$. High serum OPG was associated with significantly lower overall survival and disease-free survival rates (both $\mathrm{P}=0.001$ ), and was correlated with advanced tumor stages $(\mathrm{P}<0.0001)$, high tumor grades $(\mathrm{P}<0.0001)$ and the occurrence of disease relapse $(\mathrm{P}=0.001)$. Serum p53 and urine telomerase did not demonstrate prognostic significance. These findings indicate that serum OPG level may be used as a diagnostic tool and a prognostic variable for patients with muscle invasive bladder cancer. Future trials are required to elucidate its therapeutic role in such patients.
\end{abstract}

\section{Introduction}

Bilharziasis (schistosomiasis) has been endemic in Egypt, with the intensity of infection correlated to the development of bladder cancer (1). Bladder cancer constitutes $30 \%$ of all cases of cancer attended at the National Cancer

Correspondence to: Dr Mohamed I. El-Sayed, Department of Radiotherapy, South Egypt Cancer Institute, Assiut University, El-Nasr Towers, Building A2, Flat 907, 7156 Ahmed Hassan Al-Bakory Street, Assiut 71111, Egypt

E-mail:mohebel@yahoo.co.uk

Key words: biomarkers, bladder cancer, overall survival rate, disease-free survival rate
Institute in Egypt (2), with an overall incidence rate of 13.5/100,000 individuals in Egypt (3). The overall prevalence of Schistosoma haematobium (SH) infection in Egypt was $37-48 \%$ in the mid-20th century, however, this decreased to $3 \%$ by 2002 following the implementation of an antibilharzial campaign (4). In infected patients, the ova deposited in the bladder induces an inflammatory reaction, with the production of oxygen-derived free radicals. Subsequently, this may result in the production of carcinogenic compounds, including $\mathrm{N}$-nitrosamines and polycyclic aromatic hydrocarbons, leading to malignant transformation $(5,6)$. The International Agency for Research on Cancer found that the severity of infection was determined by the urinary egg count and was aggravated by smoking (7). Furthermore, a clear association between bladder cancer and SH infection was identified, with an odds ratio of between 2 and 14 (7). Hematuria, dysuria and necroturia are the main symptoms of infection, which occur as a result of due schistosomal cystitis (8). The median age of patients with schistosoma-associated bladder cancer is lower than patients with schistosoma non-associated bladder cancer. Additionally, schistosomal bladder cancer patients generally present at a later stage of disease, and represent a higher percentage of squamous cell carcinoma (SCC) cases than non-schistosomal bladder cancer patients (9). The majority of tumors associated with bilharziasis are bulky, appear fungating or ulcerative (10), and present at an advanced stage (11), due to the overlap of symptoms of early bilharzial cystitis with those of early malignant cystitis (12). In a report from the Urology and Nephrology center of Mansoura (13), SCC accounted for 59\% of 1026 cystectomy specimens in a bilharzial series. This high frequency may be related to squamous metaplasia and dysplasia, which are common in chronic bilharzial cystitis (12).

Bladder cancer possesses diverse biological characteristics resulting from various molecular alterations that lead to uncontrolled cell proliferation and metastasis; such characteristics affect the patient's prognosis (14). Patients with non-invasive bladder cancer must be closely monitored following the termination of treatment. At present, this follow-up is conducted by means of cystoscopy (an invasive procedure) and urine cytology every 3 months during the first two years, every 6 months during third and fourth years, and every 12 months 
thereafter, unless local recurrence is detected (15). A non-invasive marker is, therefore, required for the follow-up and diagnosis of bladder cancer in order to increase early detection, to decrease costs and to reduce rates of morbidity and mortality (16). Osteoprotegerin (OPG), a cytokine of the tumor necrosis factor (TNF) receptor super-family that is responsible for inhibiting osteoclastogenesis $(17,18)$, may have clinical value as a prognostic marker for patients with bladder carcinoma (19).

Destruction of tumor cells by the immune system is prevented by the development of resistance to TNF-related apoptosis-inducing ligand (TRAIL)-induced toxicity through expression of functional receptors or overexpression of decoy receptors on tumor cell membranes (20). OPG, a soluble decoy receptor for TRAIL, protects tumor cells from TRAIL-mediated apoptosis through binding to TRAIL and inhibiting its activity. As a result, OPG may contribute to tumor progression (19).

The tumor suppressor p53 is crucial in the regulation of cell cycle progression and apoptosis under genotoxic conditions (21). In human cancers, p53 mutations are the most frequent genetic defect (22). Mutations in the $\mathrm{p} 53$ protein often result in a prolonged half-life of the protein compared with wild-type p53, leading to its accumulation in cell nuclei, which may then be detected by immunohistochemistry (23).

Telomeres are regions located at the end of human chromosomes that function to stabilize and protect chromosomes $(24,25)$. The ends of the telomeres shorten with successive cell cycles until a critical length is reached, after which cell division results in their breakdown (26). The ribonucleoprotein enzyme telomerase is responsible for maintaining the length of telomeres by adding telomere repeats. This enzyme is inactivated in normal human epithelial tissue; however, it is reactivated in neoplasia (27). The enzymatic activity of telomerase may be measured using a telomeric repeat amplification protocol (TRAP) assay (24).

The aim of the current study was to evaluate the role of pretreatment serum OPG and p53 levels and urine telomerase levels as prognostic factors in patients with muscle-invasive bladder cancer.

\section{Materials and methods}

Patients. The current prospective study was conducted in the Departments of Radiotherapy and Clinical Pathology of the South Egypt Cancer Institute, Assiut University (Assiut, Egypt), in the period between June 1st, 2007, and June 1st, 2014. A total of 2,100 patients with non-metastatic muscle-invasive bladder cancer [clinical tumor-node-metastasis (TNM) stage $\mathrm{T} 2-4, \mathrm{~N} 0, \mathrm{M} 0]$ were selected. However, due to limited funding, only 65 of these patients and 15 healthy individuals were included. The study protocol was approved by the local institutional review board of South Egypt Cancer Institute (study ID no. IORG0006563; approval no. 190), Assiut University. Written informed consent was obtained from all patients.

For each patient, details of medical history were documented. In addition, all patients were subjected to physical examination, routine laboratory investigations, abdominopelvic computed tomography (CT) scans with contrast, chest X-ray and, if indicated, bone scans. A histopathological diagnosis
Table I. Characteristics of bladder cancer patients $(\mathrm{n}=65)$.

\begin{tabular}{lc}
\hline Variable & Value \\
\hline Gender, $\mathrm{n}(\%)$ & \\
Female & $10(15.4)$ \\
Male & $55(84.6)$ \\
Tumor stage, $\mathrm{n}(\%)$ & \\
T2 & $22(33.9)$ \\
T3 & $35(53.8)$ \\
T4 & $8(12.3)$ \\
Pathological type, $\mathrm{n}(\%)$ & \\
Transitional cell carcinoma & $49(75.4)$ \\
Squamous cell carcinoma & $16(24.6)$ \\
Bilharzial status and grade, $\mathrm{n}(\%)$ & \\
NB-LG & $19(29.2)$ \\
B-LG & $11(16.9)$ \\
NB-HG & $17(26.2)$ \\
B-HG & $18(27.7)$ \\
Laboratory tumor markers (mean \pm SD) & \\
OPG (pg/ml) & $211.5 \pm 80.8$ \\
p53 ( $\mu$ g/ml) & $27.3 \pm 11.6$ \\
Telomerase $(\mu \mathrm{g}$ protein/assay) & $13.9 \pm 6.2$ \\
Treatment modality, $\mathrm{n}(\%)$ & \\
Total cystectomy and postoperative RT & $46(70.8)$ \\
Trimodal therapy (TUR+chemoradiation) & $19(29.2)$ \\
\hline
\end{tabular}

NB-LG, non-bilharzial low grade; B-LG, bilharzial low grade; NB-HG, non-bilharzial high grade: B-HG, bilharzial high grade; SD, standard deviation; OPG, osteoprotegerin; RT, radiotherapy; TUR, transurethral resection.

of the bladder mass was determined through cystoscopy and biopsy. Schistosomiasis was diagnosed via cystoscopy based on the presence of schistosoma eggs and peri-oval granulomas in histopathological specimens. According to World Health Organization System for tumor grading (2004) (28) and a previous Malaysian study (29), patients were subdivided into non-bilharzial low-grade $(n=19)$, bilharzial low-grade $(n=11)$, non-bilharzial high-grade $(n=17)$ and bilharzial high-grade $(n=18)$ bladder cancer groups.

Laboratory assays. Samples from all patients and healthy individuals underwent laboratory assays as follows. Serum was isolated from blood samples and subjected to OPG and p53 detection by enzyme-linked immunosorbent assay (ELISA) using a Human Osteoprotegerin (OPG) ELISA kit (TNFRSF 11B; RayBiotech, Inc., Norcross, GA, USA) and p53 ELISA kit (p53 Instant One ${ }^{\mathrm{TM}}$ ELISA; eBioscience, Inc., San Diego, CA, USA) respectively. An EVOLIS System (Bio-Rad Laboratories, Inc., Hercules, CA, USA) was used to measure absorbance at $450 \mathrm{~nm}$.

Urine samples obtained from patients and healthy individuals were subjected to telomerase activity measurement using a polymerase chain reaction (PCR)-ELISA technique with a thermal cycler PTC-100 Thermal Cycler 
Table II. Laboratory biomarkers in cancer patients and healthy individuals.

Level, mean \pm standard deviation

Variable

Healthy individuals $(\mathrm{n}=15)$

Bladder cancer patients $(n=65)$

P-value

\begin{tabular}{lcrr}
\hline Serum OPG $(\mathrm{pg} / \mathrm{ml})$ & $62.3 \pm 15.7$ & $214.9 \pm 80.4$ & $<0.0001$ \\
Serum p53 $(\mu \mathrm{g} / \mathrm{ml})$ & $11.4 \pm 1.9$ & $27.3 \pm 11.5$ & $<0.0001$ \\
Urine telomerase $(\mu \mathrm{g}$ protein/assay $)$ & $3.4 \pm 0.6$ & $13.9 \pm 6.1$ & $<0.0001$ \\
\hline
\end{tabular}

OPG, osteoprotegerin.

Table III. Univariate analysis of prognostic factors affecting OAS and DFS rates.

\begin{tabular}{|c|c|c|c|c|}
\hline \multirow[b]{2}{*}{ Variable } & \multicolumn{2}{|c|}{ 3-year OAS } & \multicolumn{2}{|c|}{ 3-year DFS } \\
\hline & Rate, \% & P-value & Rate, \% & P-value \\
\hline Age, years & & 0.280 & & 0.180 \\
\hline$<60$ & 66.6 & & 66.6 & \\
\hline$\geq 60$ & 52.7 & & 50.9 & \\
\hline Gender & & 0.240 & & 0.210 \\
\hline Female & 78.8 & & 78.8 & \\
\hline Male & 56.0 & & 54.4 & \\
\hline Bilharzial status and grade & & 0.032 & & 0.015 \\
\hline NB-LG & 84.2 & & 84.2 & \\
\hline B-LG & 68.2 & & 68.2 & \\
\hline NB-HG & 52.9 & & 52.9 & \\
\hline B-HG & 42.9 & & 28.6 & \\
\hline Tumor stage & & $<0.001$ & & $<0.001$ \\
\hline $\mathrm{T} 2$ & 95.5 & & 95.5 & \\
\hline $\mathrm{T} 3$ & 53.8 & & 50.1 & \\
\hline $\mathrm{T} 4$ & $25.0^{\mathrm{a}}$ & & $25.0^{\mathrm{a}}$ & \\
\hline Pathological type & & 0.190 & & 0.260 \\
\hline Transitional cell carcinoma & 65.7 & & 61.1 & \\
\hline Squamous cell carcinoma & 48.6 & & 48.6 & \\
\hline Treatment modality & & 0.720 & & 0.890 \\
\hline $\mathrm{RC}$ and postoperative $\mathrm{RT}$ & 60.9 & & 59.3 & \\
\hline TUR and CRT & 54.0 & & 54.0 & \\
\hline
\end{tabular}

a2-year survival rate. OAS, overall survival; DFS, disease-free survival; NB-LG, non-bilharzial low grade; B-LG, bilharzial low grade; NB-HG, non-bilharzial high grade; B-HG, bilharzial high grade; RC, radical cystectomy; RT, radiotherapy; TUR, transuretheral resection; CRT, chemoradiotherapy.

(Bio-Rad Laboratories, Inc.) and EVOLIS system (Bio-Rad Laboratories, Inc.). A TRAP kit (TeloTAGGG Telomerase

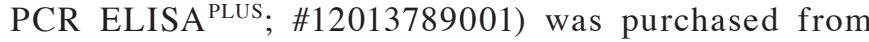
Roche Diagnostics GmbH (Mannheim, Germany) and used according to manufacturer's instructions. Telomeric repeats (TTAGGG) were added to the 3 ' end of a biotin-labelled synthetic P1-TS primer. These elongation products, as well as the internal standard (IS) in the same reaction vessel to avoid false negative results, were amplified by PCR using the primers P1-TS and P2. The Telo TAGGG Telomerase
PCR ELISA ${ }^{\text {PLUS }}$ kit contained an IS that produces a 216-bp PCR product, long enough not to interfere with making telomerase ladder visible $(30,31)$. The primer sequences were as follows: P1-TS, anchored complementary telomerase, 5'-GCGCGG[CTAACC] $]_{3}$-3'; P2, 5'-AATCCGTCGAGCAGA GTTAG[GGTTAG] $]_{4-7}-3^{\prime}$ (where subscript numbers represent maximum telomeric repeats). Sample, negative control (NC) and control template (CT) were added to separate tubes at a volume of $1 \mu \mathrm{l}$. For each, $25 \mu \mathrm{l}$ reaction mixture and $5 \mu 1$ IS were added. The applied PCR protocol was one cycle for 


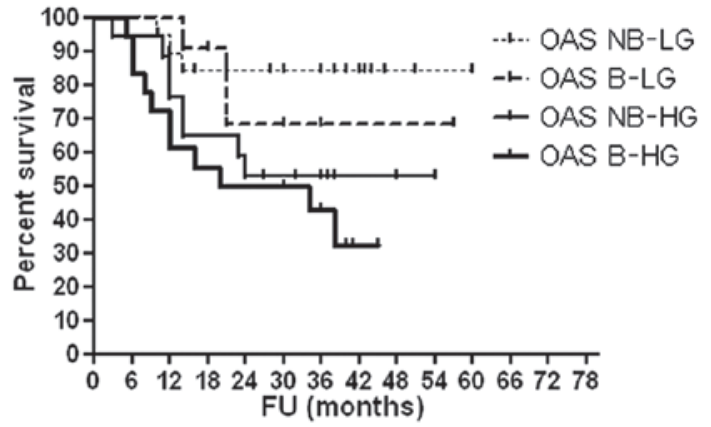

Figure 1. OAS according to histological grade and bilharzial status. OAS, overall survival; NB-LG, non-bilharzial low grade; B-LG, bilharzial low grade; NB-HG, non-bilharzial high grade; B-HG, bilharzial high grade; FU, follow-up.

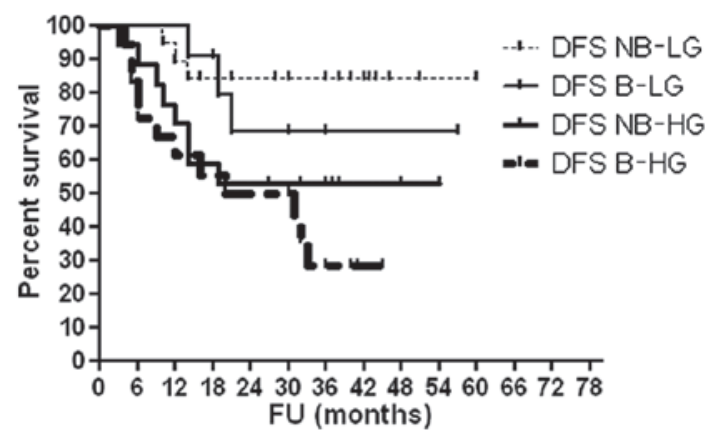

Figure 2. DFS according to histologic grade and bilharzial status. DFS, disease-free survival; NB-LG, non-bilharzial low grade; B-LG, bilharzial low grade; NB-HG, non-bilharzial high grade; B-HG, bilharzial high grade; FU, follow-up.

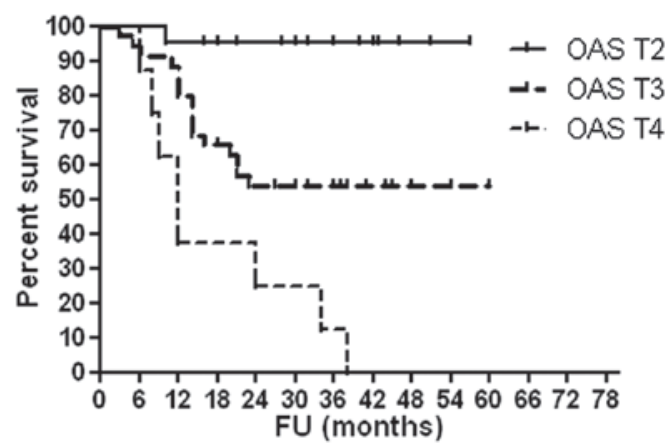

Figure 3. OAS according to disease stage. OAS, overall survival; T, tumor stage; FU, follow-up.

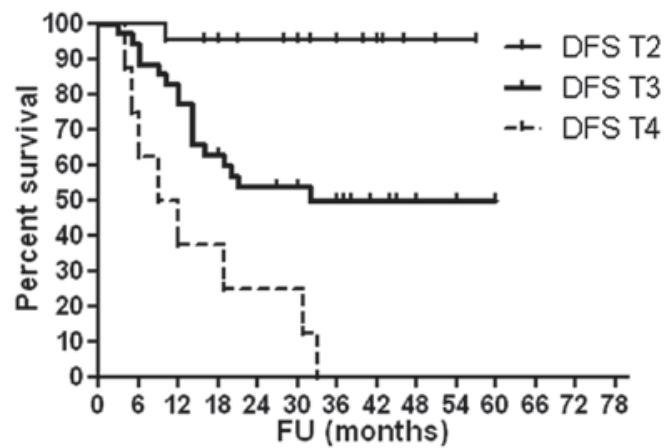

Figure 4. DFS according to disease stage. DFS, disease-free survival; T, tumor stage; FU, follow-up.
Table IV. Cox regression stepwise OAS and DFS analyses according to laboratory markers.

\begin{tabular}{lcc}
\hline Variable & OAS rate & DFS rate \\
\hline OPG & $\mathrm{P}=0.001 ; \mathrm{HR}, 1.01 ;$ & $\mathrm{P}=0.001 ; \mathrm{HR}, 1.01 ;$ \\
& $95 \% \mathrm{CI}, 1-1.01$ & $95 \% \mathrm{CI}, 1-1.01$ \\
p53 & $\mathrm{P}=0.97$ & $\mathrm{P}=0.82$ \\
Telomerase & $\mathrm{P}=0.61$ & $\mathrm{P}=0.72$ \\
\hline
\end{tabular}

OAS, overall survival; DFS, disease free survival; OPG, osteoprotogerin; HR, hazard ratio; CI, confidence interval.

Table V. Disease relapse.

\begin{tabular}{lrr}
\hline Disease relapse & $\mathrm{n}$ & $\%$ \\
\hline Local recurrence & 4 & 6.2 \\
Distant metastases & 7 & 10.8 \\
Mixed relapse & 1 & 1.5 \\
Total & 12 & 18.5 \\
\hline
\end{tabular}

primer elongation (10-30 min at $25^{\circ} \mathrm{C}$ ) followed by one cycle of telomerase inactivation $\left(5 \mathrm{~min}\right.$ at $\left.94^{\circ} \mathrm{C}\right)$. The subsequent amplification scheme was 30 cycles of denaturation for $30 \mathrm{sec}$ at $94^{\circ} \mathrm{C}$, annealing for $30 \mathrm{sec}$ at $50^{\circ} \mathrm{C}$, and polymerization for $90 \mathrm{sec}$ at $72^{\circ} \mathrm{C}$. Finally, an additional extension was performed for $10 \mathrm{~min}$ at $72^{\circ} \mathrm{C}$. The denatured and hybridized products were added to streptavidin-coated plates (Roche Diagnostics $\mathrm{GmbH}$ ). The immobilized amplicons were detected using horseradish peroxidase (HRP)-conjugated anti-digoxigenin (DIG) antibody with DIG-labelled detection probes from the Telo TAGGG Telomerase PCR ELISA ${ }^{\text {PLUS }}$ kit (P3 T and P3 IS for the sample and internal standard, respectively; Roche Diagnostics $\mathrm{GmbH}$ ) for $1 \mathrm{~h}$ at $37^{\circ} \mathrm{C}$, which were complementary to the telomeric repeat sequence. Sheep polyclonal antibody conjugated to HRP was used for $1 \mathrm{~h}$ at $37^{\circ} \mathrm{C}$ to prepare conjugate (working) solution (dilution, 1:20). Following preparation, anti-DIG-HRP conjugate working solution $(10 \mathrm{mU} / \mathrm{ml})$ was added for $30 \mathrm{~min}$ at room temperature, followed by washing five times with washing buffer $(250 \mu 1)$. Tetramethylbenzidine substrate was added then $100 \mu 1$ stopping solution (Roche Diagnostics $\mathrm{GmbH}$ ) was added. Absorbance was measured at $450 \mathrm{~nm}$ and relative telomerase activity (RTA) was determined using the following formula:

$$
\mathrm{RTA}=\frac{\left(\mathrm{A}_{\mathrm{S}}-\mathrm{A}_{\mathrm{S}, 0}\right) / \mathrm{A}_{\mathrm{S}, \mathrm{IS}}}{\left(\mathrm{A}_{\mathrm{TS} 8}-\mathrm{A}_{\mathrm{TS} 8,0}\right) / \mathrm{A}_{\mathrm{TS} 8, \mathrm{IS}}}
$$

where $A_{S}$ was the absorbance of the sample, $A_{S, 0}$ was the absorbance of the RNase-treated sample, $A_{S, I S}$ was the absorbance of the IS of the sample, $\mathrm{A}_{\mathrm{TS} 8}$ was the absorbance of the control template (TS8), $\mathrm{A}_{\mathrm{TS} 8,0}$ was the absorbance of the lysis buffer, and $\mathrm{A}_{\mathrm{TS} 8, \mathrm{IS}}$ was the absorbance of the IS of the control template. 
Table VI. Association between serum OPG level and different prognostic variables.

\begin{tabular}{|c|c|c|}
\hline Variable & $\mathrm{OPG}, \mathrm{pg} / \mathrm{ml} ;$ mean $\pm \mathrm{SD}$ & P-value \\
\hline Bilharzial status and grade & & $<0.0001$ \\
\hline NB-LG & $128.4 \pm 25.3$ & \\
\hline B-LG & $163.2 \pm 17.6$ & \\
\hline NB-HG & $244.1 \pm 20.9$ & \\
\hline B-HG & $310.3 \pm 49.9$ & \\
\hline Tumor stage & & $<0.0001$ \\
\hline $\mathrm{T} 2$ & $157.1 \pm 48.6$ & \\
\hline $\mathrm{T} 3$ & $231.4 \pm 77.1$ & \\
\hline $\mathrm{T} 4$ & $301.8 \pm 50.9$ & \\
\hline Histopathological type & & 0.37 \\
\hline Transitional cell carcinoma & $220.1 \pm 83.1$ & \\
\hline Squamous cell carcinoma & $199.1 \pm 71.5$ & \\
\hline Age, years & & 0.092 \\
\hline$<60$ & $196.2 \pm 84.8$ & \\
\hline$\geq 60$ & $230.0 \pm 74.4$ & \\
\hline Gender & & 0.72 \\
\hline Female & $206.5 \pm 67.7$ & \\
\hline Male & $216.5 \pm 82.9$ & \\
\hline Disease relapse & & 0.001 \\
\hline Relapse & $285.0 \pm 60.8$ & \\
\hline No relapse & $199.1 \pm 76.1$ & \\
\hline
\end{tabular}

OPG, osteoprotegerin; SD, standard deviation; NB-LG, non-bilharzial low-grade; B-LG, bilharzial low-grade; NB-HG, non-bilharzial high-grade; B-HG, bilharzial high-grade.

Radiotherapy. Patients were non-randomly assigned into one of two groups. Group 1 included patients who underwent radical cystectomy (anterior pelvic exenteration in female patients) and postoperative radiotherapy using 2-dimensional planning and a 3-field technique, with a radiation dose of $50 \mathrm{~Gy} / 25$ fractions over 5 weeks using $15 \mathrm{MV}$ photons. Group 2 included patients who underwent trimodal therapy [complete transurethral resection (TUR), and concurrent chemo-radiotherapy]. Radiotherapy was initiated 4-6 weeks after TUR using 3-dimensional planning in two phases. In phase I, the clinical target volume (CTV) included the urinary bladder, proximal urethra (and prostate in male patients) and regional lymph nodes (hypogastric, external iliac and obturator nodes). The planning target volume (PTV), including the CTV plus a $1 \mathrm{~cm}$ margin, was treated with total dose of 46 Gy in 23 fractions, with 5 fractions administered per week. In phase II, the PTV included the whole bladder plus $2 \mathrm{~cm}$ margins, and received an additional total dose of $20 \mathrm{~Gy}$ in 10 fractions with $15 \mathrm{MV}$ photons.

Chemotherapy. Gemcitabine was administered at $30 \mathrm{mg} / \mathrm{m}^{2}$ by a $30-\mathrm{min}$ intravenous infusion prior to radiation therapy sessions twice weekly. Follow-up examinations were performed routinely every 3 months following treatment. Abdominopelvic CT scans, chest radiography and, for group 2 patients, cystoscopy were performed annually.
Statistical methods. The study cut-off point was June 1st, 2014. Overall survival (OAS) and disease-free survival (DFS) rates were estimated by the Kaplan-Meier method using the GraphPad Prism program (version 5; GraphPad Software, Inc., La Jolla, CA, USA). The log-rank test was used to examine differences in OAS and DFS rates. Comparison of mean values of OPG in different groups was conducted using a one-way analysis of variance. $\mathrm{P}<0.05$ was considered to indicate statistical significance.

\section{Results}

Study subjects. A total of 65 patients were recruited into the study. Patient characteristics are listed in Table I. The median age of the patients was 60 years. The majority of patients were male [55 patients; $84.6 \%$; male to female ratio, 5.5:1) and presented with T3 disease stage (35 patients; $54 \%$ ), transitional cell carcinoma pathological type (49 patients; $75.5 \%$ ), and high-grade disease (35 patients; $54 \%$ ). A positive history of bilharziasis was documented in 29 patients (44.5\%).

Radical cystectomy followed by adjuvant radiotherapy was conducted in the vast majority of patients $(71 \%)$, while trimodal therapy was conducted in the remaining $29 \%$. The median follow-up time from the date of enrollment was 30 months, and ranged from 3 to 60 months.

Biomarker levels. Laboratory biomarkers were assessed in cancer patients and healthy individuals (Table II). The mean 
values of serum OPG, serum p53 and urine telomerase were significantly higher in bladder cancer patients than in healthy individuals $(\mathrm{P}<0.0001)$.

Survival rates. After a median follow-up period of 30 months, the 3-year OAS and DFS rates were 59 and 58\%, respectively. There were no significant differences between OAS and DFS rates according to age, gender, pathological type, treatment modality, serum p53 level or urine telomerase level (Tables III and IV). However, significant differences in 3 -year OAS and DFS rates were associated with T stage (both $\mathrm{P}<0.0001)$, histological grade and bilharzial status (OAS, $\mathrm{P}=0.032$; DFS, 0.015), and serum OPG level (both $\mathrm{P}=0.001$ ).

As indicated in Table $\mathrm{V}$, only 4 patients $(6 \%)$ developed local recurrence, 7 patients $(11 \%)$ developed distant metastases ( 4 in the bones, 2 in the lungs and 1 in the bones and liver) and 1 patient $(1.5 \%)$ developed mixed local and distant (bones and lungs) metastases.

Association between serum OPG level and prognostic variables. As shown in Table VI, high serum OPG levels were associated with advanced $\mathrm{T}$ stage $(\mathrm{P}<0.0001)$, high histological grade $(\mathrm{P}<0.0001)$ and occurrence of disease relapse $(\mathrm{P}=0.001)$. Figs. 1-4 show OAS and DFS rates according to histological grade and disease stage.

\section{Discussion}

Identification of biomarkers for bladder cancer may improve the screening and diagnosis for this disease, and aid in determining its prognosis. Ideal biomarkers would be those that may be detected non-invasively and rapidly, that are easy to obtain, use and interpret, are inexpensive and have high accuracy $(32,33)$. A large number of molecular markers that have potential prognostic value have been determined in previous studies of molecular biology and genetics (19,23,34-38), and include serum OPG, serum p53 and urine telomerase.

In the present study, levels of serum OPG and p53 protein, and urine telomerase were identified to be significantly higher $(\mathrm{P}<0.0001)$ in patients with bladder carcinoma than in healthy individuals. This is in agreement with the findings of a previous study by Mizutani et al (19), in which it was reported that the mean serum OPG concentration in patients with bladder carcinoma was $\sim 3$ times greater than the mean concentration in healthy volunteers. Shimada et al (39) reported that surveillance of serum p53 antibodies may be useful in detecting various types of malignant tumors, including bladder cancer. Telomerase is activated in cancer cells, but not in normal somatic cells; therefore, its detection may be used as a diagnostic marker for cancer (40). Patients with urothelial tumors of all grades exhibit telomerase activity in voided urine (41).

With a median follow-up of 30 months, the 3-year OAS and DFS rates were 59 and $58 \%$, respectively, in the present study. Survival rates in the current study are comparable to those reported in previous studies $(42,43)$. The postoperative radiotherapy (in cystectomy group) and the trimodal therapy (i.e. TUR, and chemoradiation, in bladder preservation group) resulted in a relatively low relapse rate in the present study $(18.5 \%)$. Zaghloul et al (44) demonstrated that adjuvant radiation therapy improve local control rate, and that the therapeutic benefit of postoperative irradiation was consistent for all tumor types, histological grades and pathological stages in terms of DFS and local control.

Among the investigated variables in the current study, only $\mathrm{T}$ stage, bilharzial status and histological grade, and serum OPG biomarker level significantly influenced the rates of OAS $(\mathrm{P}<0.0001, \mathrm{P}=0.032$ and $\mathrm{P}=0.001$, respectively) and $\mathrm{DFS}$ $(\mathrm{P}<0.0001, \mathrm{P}=0.015$ and $\mathrm{P}=0.001$, respectively). Numerous studies have previously analyzed prognostic factors in patients with bladder cancer treated by radical cystectomy, and pathological stage is considered to be the most important prognostic factor in such patients (45-51).

In contrast to OPG in the present study, serum p53 and urine telomerase were not significantly associated with survival rates. Regarding p53 status as a prognostic factor in muscle-invasive bladder cancer, results are contradictory (23). Schmitz-Dräger et al (52) conducted a meta-analysis of all published research on the association between p53 positivity and the prognosis of patients with bladder cancer. In the majority of trials ( 5 of 7 ) of muscle-invasive bladder cancer, p53 was not regarded as an independent prognostic marker of disease progression. The findings of the present study are in agreement with the results of this meta-analysis. It was also stated that, although urinary telomerase could be a potentially useful urinary tumor marker, its use for diagnosis in symptomatic patients or its impact during surveillance is still unknown (40). Furthermore, normalization and standardization of the assays used to evaluate this is required before they may become valuable in clinical practice (40).

In previous studies investigating the use of serum OPG level as a prognostic marker, elevated levels were reported to be associated with poor prognosis (19,53-55). The 5-year disease-specific survival rate of patients with muscle-invasive bladder carcinoma was determined to be greater for those with low serum OPG levels compared with those exhibiting high serum OPG levels. Such findings indicate that OPG concentration may be a significant prognostic factor in patients with this disease, with low serum OPG levels indicating a favorable prognosis.

In the current study, serum OPG levels in patients with bladder carcinoma were analyzed according to patient's age and gender, disease stage, tumor grade, pathological type and occurrence of disease relapse. High serum OPG was identified to be associated with advanced $\mathrm{T}$ stage, high histological grade $(\mathrm{P}<0.0001)$ and the presence of relapse $(\mathrm{P}=0.001)$. This is in agreement with studies by Mizutani et al (19) and Holen and Shipman (56), who reported high serum OPG was associated with advanced disease stage, high grade and low 5-year disease-specific survival rate. One limitation of the present study is that the analysis was restricted as patient selection for treatment in the two treatment groups was not randomized.

Despite the advent of effective chemotherapy and modern radiation therapy techniques, treatment outcome of bladder cancer is unsatisfactory as local recurrence and distant metastases are major problems. Therefore, treatment protocols inhibiting OPG production may increase TRAIL-mediated toxicity of malignant cells and thus may improve treatment results (19). This necessitates future trials in larger patient populations with longer follow-up, to clarify the prognostic role of OPG in cancers of different stages, pathological types and grades. 


\section{References}

1. Mostafa MH, Sheweita SA and O'Connor PJ: Relationship between schistosomiasis and bladder cancer. Clin Microbiol Rev 12 97-111, 1999.

2. Sherif M and Ibrahim AS: The incidence of cancer in Egypt. In: The Profile of Cancer in Egypt. Arab World Printing House, Cairo, pp179-190, 1987.

3. Ibrahim AS, Khaled HM, Mikhail NH, Baraka H and Kamel H: Cancer incidence in Egypt: Results of the national population-based cancer registry program. J Cancer Epidemiol 2014: 1-18, 2014.

4. Prevalence of schistosomiasis in Egypt over time. Department of Endemic Diseases, Ministry of Health and Population, Egypt, 2004

5. Rosin MP, Saad el Din Zaki S, Ward AJ and Anwar WA: Involvement of inflammatory reactions and elevated cell proliferation in the development of bladder cancer in schistosomiasis patients. Mutat Res 305: 283-292, 1994.

6. Marletta MA: Mammalian synthesis of nitrite, nitrate, nitric oxide, and N-nitrosating agents. Chem Res Toxicol 1: 249-257, 1988.

7. International Agency for Research on Cancer: IARC Monographs on the Evaluation of Carcinogenic Risks to Humans (Vol 61) Schistosomes, Liver flukes and Helicobacter pylori. IARC Press, Lyon, 1994.

8. Zaghloul MS: Bladder cancer and schistosomiasis. J Egypt Nat Canc Inst 24: 151-159, 2012

9. Zaghloul MS: Radiation as adjunctive therapy to cystectomy for bladder cancer: Is there a difference for bilharzial association? Int J Radiat Oncol Biol Phys 28: 783, 1994.

10. Khalaf I, El-Mallah E, Elsotouhi I, Abu-Zeid H and Elmeligy A: Pathologic pattern of invasive bladder carcinoma: Impact of bilharziasis. Afr J Urol 14: 90-97, 2010.

11. el-Bolkainy MN, Ghoneim MA and Mansour MA: Carcinoma of the bilharzial bladder in Egypt. Clinical and pathological features. Br J Urol 44: 561-570, 1972.

12. Abol-Enein H, Kava BR and Carmack AJ: Nonurothelial cancer of the bladder. Urology 69: 93-104, 2007.

13. Ghoneim MA, el-Mekresh MM, el-Baz MA, el-Attar IA and Ashamallah A: Radical cystectomy for carcinoma of the bladder: Critical evaluation of the results in 1,026 cases. J Urol 158 393-399, 1997.

14. Ha YS, Kim JS, Yoon HY, Jeong P, Kim TH, Yun SJ, Lee SC, Kim GY, Choi YH, Moon SK, et al: Novel combination markers for predicting progression or nonmusclc invasive bladder cancer. Int J Cancer 131: E501-E507, 2012.

15. Parmar MK, Freedman LS, Hargreave TB and Tolley DA: Prognostic factors for recurrence and followup policies in the treatment of superficial bladder cancer. Report from the british medical research council subgroups on superficial bladder cancer (Urological Cancer Working Party). J Urol 142: 284-288, 1989.

16. Wadhwa N, Jatawa SK and Tiwari A: Non-invasive urine based tests for the detection of bladder cancer. J Clin Pathol 65 970-975, 2012

17. Golledge J, McCann M, Mangan S, Lam A and Karan M: Osteoprotegerin and osteopontin are expressed at high concentrations within symptomatic carotid atherosclerosis. Stroke 35 1636-1641, 2004

18. Hellenthal FA, Buurman WA, Wodzig WK and Schurink GW: Biomarkers of abdominal aortic aneurysm progression. Part 2 Inflammation. Nat Rev Cardiol 6: 543-552, 2009.

19. Mizutani Y, Mutsubara H, Yamamoto K, Nan Li Y, Mikami K, Okihara K, Kawauchi A, Bonavida B and Miki T: Prognostic significance of serum osteoprotegerin levels in patients with bladder carcinoma. Cancer 101: 1794-1802, 2004.

20. Makimovic-Ivanic D, Stocic-Grujicic S, Nicoletti F and Mijatovic S: Resistance to TRAIL and how to surmount it. Immunol Res 52: 157-168, 2012.

21. Spike BT and Wahl GM: p53, stem cells, and reprogramming: Tumor suppression beyond guarding the genome. Genes Cancer 2 : 404-419, 2011

22. Hollstein M, Sidransky D, Vogelstein B and Harris CC: p53 mutations in human cancers. Science 253: 49-53, 1991.

23. Habuchi T, Marberger M, Droller MJ, Hemstreet GP III, Grossman HB, Schalken JA, Schmitz-Dräger BJ, Murphy WM, Bono AV, Goebell P, et al: Prognostic markers for bladder cancer: International consensus panel on bladder tumor markers. Urology 66 (6 Suppl 1): 64-74, 2005

24. Kim NW, Piatyszek MA, Prowse KR, et al: Specific association of human telomerase activity with immortal cells and cancer. Science 266: 2011-2015, 1994.
25. Yoshida K, Sugino T, Tahara H, Woodman A, Bolodeoku J, Nargund V, Fellows G, Goodison S and Tahara E: Telomerase activity in bladder carcinoma and its implication for non-invasive diagnosis by detection of exfoliated cancer cells in urine. Cancer 79: 362-369, 1997.

26. Hodes RJ: Telomere length, aging, and somatic cell turnover. J Exp Med 190: 153-156, 1999.

27. $\mathrm{Mu} \mathrm{J}$ and Wei LX: Telomere and telomerase in oncology. Cell Res 12:1-7, 2002

28. Eble JN, Sauter G, Epstein JI, and Sesterhenn IA: World Health Organization classification of tumors: Pathology and genetics of tumors of the urinary system and male genital organs. In collaboration with the International Academy of Pathology (IAP): 139-390, 2004

29. Abdulamir AS, Hafidh RR, Kadhim HS, Abubakar F: Tumor markers of bladder cancer: The schistosomal bladder tumors versus non-schistosomal bladder tumors. J Exp Clin Cancer Res 28: 27, 2009.

30. Wright WE, Shay JW and Piatyszek MA: Modifications of a telomeric repeat amplification protocol (TRAP) result in increased reliability linearity and sensitivity. Nucl Acids Res 23: 3794-3795, 1995.

31. Kim NW and Wu F: Advances in quantification and characterization of telomerase activity by the telomeric repeat amplification (TRAP). Nucl Acids Res 25: 2595- 2597, 1997.

32. Burchardt M, Burchardt T, Shabsigh A, De La Taille A, Benson MC and Sawczuk I: Current concepts in biomarker technology for bladder cancers. Clin Chem 46: 595-605, 2000.

33. Selmy MA, Ibrahim GH, EI Serafi TI and Ghobeish AA: Evaluation of urinary proepithelin as potential biomarker for bladder cancer detection and prognosis in Egyptian patients. Cancer biomarker 7: 163-170, 2010.

34. El-Kenawy A, El-Kott AF and Khalil AM: Prognostic value of p53 and MDM2 expression in bilharziasis-associated squamous cell carcinoma of the urinary bladder. Int J Biol Markers 18: 284-289, 2003.

35. Hemal AK, Khaitan A, Dinda AK, Gupta NP, Seth A, Dogra PN and Nabi G.: Prognostic significance of p53 nuclear overexpression in patients of muscle invasive urinary bladder carcinoma treated with cystectomy. Urol Int 70: 42-46, 2003.

36. Tsai YS, Tzai TS, Chow NH, Yang WH, Tong YC, Lin JS, Chang CC, Cheng HL and Lin YM: Prognostic values of p53 and HER-2/neu coexpression in invasive bladder cancer in Taiwan. Urol Int 71: 262-270, 2003.

37. Kelsey KT, Hirao T, Schned A, Hirao S, Devi-Ashok T, Nelson HH, Andrew A and Karagas MR: A population-based study of immunohistochemical detection of p53 alteration in bladder cancer. Br J Cancer 90: 1572-1576, 2004

38. Shariat SF, Casella R, Khoddami SM, et al. Urine detection of survivin is a sensitive marker for the noninvasive diagnosis of bladder cancer. J Urol, 171: 626-630, 2004.

39. Shimada H, Ochiai T and Nomura F; Japan p53 Antibody Research Group: Titration of serum p53 antibodies in 1,085 patients with various types of malignant tumors. A multiinstitutional analysis by the Japan p53 Antibody Research Group. Cancer 97: 682-689, 2003.

40. Lamarca A and Barriuso J: Urine telomerase for diagnosis and surveillance of bladder cancer. Adv Urol 2012: 693631, 2012.

41. Kavaler E, Landman J, Chang Y, Droller MJ and Liu BC: Detecting human bladder carcinoma cells in voided urine samples by assaying for the presence of telomerase activity. Cancer 82: 708-714, 1998 .

42. Lee CT, Madii R, Daignault S, Dunn RL, Zhang Y, Montie JE and Wood DP Jr: Cystectomy delay more than 3 months from initial bladder cancer diagnosis results in decreased disease specific and overall survival. J Urol 175: 1262-1267, 2006.

43. Sonpavde G, Khan MM, Lerner SP, Svatek RS, Novara G, Karakiewicz PI, Skinner E, Tilki D, Kassouf W, Fradet Y, et al: Disease-free survival at 2 or 3 years correlates with 5 -year overall survival of patients undergoing radical cystectomy for muscle invasive bladder cancer. J Urol 185: 456-461, 2011.

44. Zaghloul MS, Awwad HK, Akoush HH, Omar S, Soliman O and el Attar I: Postoperative radiotherapy of carcinoma in bilharzial bladder: Improved disease free survival through improving local control. Int J Radiat Oncol Biol Phys 23: 511-517, 1992.

45. Bassi P, Ferrante GD, Piazza N, Spinadin R, Carando R, Pappagallo G and Pagano F: Prognostic factors of outcome after radical cystectomy for bladder cancer: A retrospective study of a homogeneous patient cohort. J Urol 161: 1494-1497, 1999. 
46. Harada K, Sakai I, Hara I, Eto H and Miyake H: Prognostic significance of vascular invasion in patients with bladder cancer who underwent radical cystectomy. Int J Urol 12: 250-255, 2005.

47. Antunes AA, Nesrallah LJ, Dall'Oglio MF, Ferreira YA, Passerotti CC, Leite KR, Ortiz V and Srougi M: Analysis of prognostic factors in patients with transitional cell carcinoma of the bladder treated with radical cystectomy. Int Braz J Urol 32: 35-42, 2006.

48. Madersbacher S, Hochreiter W, Burkhard F, Thalmann GN, Danuser H, Markwalder R and Studer UE: Radical cystectomy for bladder cancer today-a homogeneous series without neoadjuvant therapy. J Clin Oncol 21: 690-696, 2003.

49. Skołyszewski J, Reinfuss M and Weiss M: Radical external beam radiotherapy of urinary bladder carcinoma. An analysis of results in 500 patients. Acta Oncol 33: 561-565, 1994.

50. Türkölmez K, Tokgöz H, Reşorlu B, Köse K and Bedük Y: Muscle-invasive bladder cancer: Predictive factors and prognostic difference between primary and progressive tumors. Urology 70 477-481, 2007.

51. Takashi M, Sakata T, Murase T, Hamajima N and Miyake K: Grade 3 bladder cancer with lamina propria invasion (pTl): Characteristics of tumor and clinical course. Nagoya J Med Sci 53: $1-8,1991$.
52. Schmitz-Dräger BJ, Goebell PJ, Ebert T and Fradet Y: p53 immunohistochemistry as a prognostic marker in bladder cancer. Playground for urology scientists? Eur Urol 38: 691-699, 2000.

53. Ito R, Nakayama H, Yoshida K, Kuraoka K, Motoshita J, Oda N, Oue N and Yasui W: Expression of osteoprotegerin correlates with aggressiveness and poor prognosis of gastric carcinoma. Virchows Arch 443: 146-151, 2003.

54. Brown JM, Vessella RL, Kostenuik PJ, Dunstan CR, Lange PH and Corey E: Serum osteoprotegerin levels are increased in patients with advanced prostate cancer. Clin Cancer Res 7: 2977-2983, 2001

55. Eaton CL, Wells JM, Holen I, Croucher PI and Hamdy FC: Serum osteoprotegerin (OPG) levels are associated with disease progression and response to androgen ablation in patients with prostate cancer. Prostate 59: 304-310, 2004.

56. Holen I and Shipman CM: Role of osteoprotegerin (OPG) in cancer. Clin Sci (Lond) 110: 279-291, 2006. 